\title{
Erratum to: Kinetic Analysis of the Thermal Decomposition of Lowland and High-Moor Peats
}

S. I. Islamova ${ }^{a, *}$, S. S. Timofeeva ${ }^{a, * *}$, A. R. Khamatgalimov ${ }^{b, * * *}$, and D. V. Ermolaev ${ }^{a, * * * *}$

${ }^{a}$ Institute of Power Engineering and Advanced Technologies, FRC Kazan Scientific Center, Russian Academy of Sciences, Kazan, 420111 Russia

${ }^{b}$ A.E. Arbuzov Institute of Organic and Physical Chemistry, FRC Kazan Scientific Center, Russian Academy of Sciences, Kazan, 420088 Russia

*e-mail: isvetulia@mail.ru

**e-mail: zvezdochka198512@mail.ru

***e-mail: ayrat_kh@iopc.ru

****e-mail: energoed@gmail.com

Received July 9, 2020

DOI: $10.3103 / \mathrm{S} 0361521920330010$

The affiliation under indication $a$ should read as follows:

${ }^{a}$ Institute of Power Engineering and Advanced Technologies, FRC Kazan Scientific Center, Russian Academy of Sciences, Kazan, 420111 Russia

The affiliation under indication $b$ should read as follows:

${ }^{b}$ A.E. Arbuzov Institute of Organic and Physical Chemistry, FRC Kazan Scientific Center, Russian Academy of Sciences, Kazan, 420088 Russia

The original article can be found online at

https://doi.org/10.3103/S0361521920030040 